\title{
Comparison of the Practical Curriculum for Pre-school Education in Chinese and American Universities
}

\author{
Yuping Cao \\ Yuxi Normal University, Yuxi Yunnan 653100 China
}

Keywords: Pre-school education; practical curriculum; comparative study.

\begin{abstract}
The practical curriculum for the major of Pre-school Education has a good effect on prevocational training of kindergarten teachers and thereby has a direct impact on the early childhood education in China. At present, the construction of the practical curriculum system in Pre-school Education in China is still far from western developed countries, which has led to a certain degree of backwardness in the construction and development of pre-school education in China. Due to the differences in social culture, educational system, preschool teachers' social status and teacher certification authentication, China must further clarify the differences between itself and America in the establish of the practical curriculum for Pre-school Education and actively learn its relevant measures and experiences, so as to build a more flexible practical curriculum system for Pre-school Education to promote the development of Pre-school Education.
\end{abstract}

\section{Introduction}

With the continuous development of pre-school education, the cultivation of applied personnel with high quality and high capacity for composite pre-school education has been an innovative practice requirement under the new situation, and it is also an important direction for the development of vocational training of pre-school education. The traditional teacher-centered teaching system cannot adapt to the development trend of current education system, and hence solving the problems existing in the higher vocational education is helpful to realize the diversity development of practical curriculum teaching for Pre-school Education. It can not only provide a good platform for the employment of students, but can also help the teaching of Pre-school Education realize the innovation of theories and methods, speeding up the specialization of Pre-school Education in China. This is an education method in line with the concept of the socialist education system and also a realistic consideration of the society's demand for high-level pre-school education professionals in the market economic system.

\section{Comparative study of the practice curriculum for the Pre-school Education in Chinese and American Universities}

\subsection{Comparison of educational philosophy}

It is pointed in American education standards for pre-school teachers that, in the process of educating pre-school teachers, it is supposed to first set out from people's needs of survival skills to realize the orientation of trained objectives. This shows that the concept of pre-school education in America is more humane. It advocates the choice of students in the cultivation of kindergarten teachers to achieve differentiated education. In the process of teaching, the school quantifies teaching contents, teaching methods and teaching effects ${ }^{[1]}$, pursues different education in different stages of education, promoting the overall quality of Pre-school Education majors.

In China, the philosophy of cultivating kindergarten teachers is blended with that of training traditional teachers in the process of pre-school education. Due to the lack of enough understanding of the philosophy of pre-school education, many Pre-school Education majors lack corresponding basic knowledge in the process of learning, including language ability and learning ability. At the same time, there are also some shortcomings in their education ability to cultivate children's thinking quality, cultural character and other aspects. Specifically, current kindergarten teachers also lack a comprehensive understanding of the training ways and channels for these following competencies. 
(1) Language ability: it is to develop children's language in social situations, including the ability to understand and express intentions and emotional attitudes by listening, speaking, reading, watching, writing and other means.

(2) Cultural Character: it refers to the understanding of Chinese and foreign cultures as well as the recognition of excellent cultures. It is the intellectual accomplishment, literary accomplishment and behavior orientation that children show under the global cultural background.

(3) The quality of thinking: it indicates the personality characteristics of children's thinking which reflect their performance level and characteristics in logical thinking, critical and creative issues as well as other aspects.

(4) Learning ability: it not only contains learning methods and strategies, but also covers the cognition and attitude to learning and life.

\subsection{Comparison of career development goals}

The primary goal of the Pre-school Education in America is to cultivate professionals who adapt to the teaching of early childhood education, and it attaches importance to improving teaching skills and practical qualities of pre-school teachers. Owing to this training goal, the curriculum arrangements, teaching hours, practice hours and contents as well as curriculum internships for Preschool Education majors in American universities are greatly related to the actual situation of early childhood education. The teaching for Pre-school Education professional is highly specialized. Its good involvement in the related knowledge, skills and professional development basically establishes the training mode for the oriented training and output of pre-school education personnel.

The teaching of Pre-school Education in China, to a large extent, neglects the professional needs of students and the cultivation objective is also unclear. Pre-school Education is mainly for pre-school children. The education mode for children in this age group is quite different from that for the general primary and secondary school students. However, it can be seen from the training mode for students of Pre-school Education in Chinese universities that, most schools have a lower orientation to students. They put the framework of Pre-school Education in that one for normal teacher education and the teaching curriculum is also not professional. Furthermore, teaching requirements cannot meet the needs of innovative early childhood education system. In other word, it highlights the theory education while ignoring the importance of practice. Secondly, in terms of the specialized courses of Pre-school Education in universities, there is no specific and detailed cultivation idea and goal, and also no specific design for the curriculum development and practical activities according to the actual needs of modern pre-school education.

\subsection{The comparison of implementation process of teaching}

In the implementation process of practical curriculum for Pre-school Education, American universities attach importance to the all-round development of students, while students are spoon-fed a great deal of knowledge in a short period of time in Chinese exam-oriented education system. Preschool Education in American universities divides students' ability tests into several parts, such as basic knowledge, skills of pre-school education, professional attitude, social practice ability, and so on, which fully realizes the rational cognition of students' exam result and the individual's ability ${ }^{[2]}$. There is no strict scoring limit in the education system of American universities. Therefore, Preschool Education majors generally have much time to develop interdisciplinary and cross-disciplinary abilities and interests in the process of individual learning, which is of great value to becoming an outstanding kindergarten teacher.

The practical curriculum of Pre-school Education in China lacks the ability to design curriculum, leading to teachers' deficiencies in professional skills. The practical curriculum design for Pre-school Education can significantly increase students' learning pleasure. It needs to be interesting, comprehensive, and functional, but at present, kindergarten teachers have obvious deficiencies in curriculum design. First of all, in terms of interestingness, the curriculum should be designed to achieve the communication between teachers and students, Teachers can share relevant short films or video movies in real time, so as to get rid of the dull blackboard teaching mode and make the preschool practice class more vivid and diverse. At present, practical curriculum design for Pre-school Education is mostly dull. Secondly, the curriculum design is a kind of perfection and synthesis of 
teaching functions. For the teaching of Pre-school Education, teaching materials and teachers are very important and complementary. Course design can not only visually present teaching materials to help learn and read, but can also ensure that teachers' explanations can be synchronized to bring young children into the scene related to the teaching contents. At present, teachers' curriculum design cannot yet reflect this comprehensive appeal, showing the lack of teachers' professional competence.

\subsection{Comparison of teachers}

Pre-school Education is equipped with qualified teachers in American universities, thanks to the good hiring approval, comments and other links. The discussion and deliberation mainly focuses on the further employment and substantive appointment, with strict steps and a certain degree of scientificity. The purpose is to ensure that high-quality and high-caliber personnel can play their part in the teacher team, thus enhancing the competitiveness of universities in the real environment. At the same time, this process will also play a stimulating role for university teachers to help them to define their actual capabilities and enhance their competitiveness. The deliberation and assessment of academic-related staff mainly covers four aspects: teaching level, scientific research achievements, on-campus services and off-campus services ${ }^{[3]}$. The exam of teaching level is mainly realized through the comprehensive check of the classroom teaching, student feedback, guidance for postgraduate students, academic research results and exploration in the new field of teaching. After students as well as the corresponding teaching team members and the person in charge show their views on a teacher through the anonymous questionnaire, the school gives a comprehensive assessment to the teacher by combining the survey results with other aspect of the teacher, such as his actual performance, capacity of publishing papers and whether has the core influence or research ability in his professional field. The assessment generally includes two aspects, namely on-campus services and off-campus services. The assessment of on-campus services is conducted by the relevant faculties and teaching office, while the other is carried out by the professional organization or government.

On the contrary, the faculty is an important factor in the development of early childhood education in China. Teachers are the guide for children in their knowledge studying, playing a key role in enlightening the wisdom and cultivating their abilities. However, there are relatively few outstanding teachers in the early childhood education system, which mainly manifest as that they do not have enough innovations in education and teaching and cannot achieve advancement in early childhood education by introducing new into traditional teaching materials. Furthermore, most kindergarten teachers also have not paid attention to the true meaning of early childhood education. In some areas, there is a serious shortage of kindergarten teachers who have received regular teaching training and the generally low quality of young children also affects the quality of teaching, which not only affects young children's learning enthusiasm but also does not helpful to the completion of the established syllabus. Hence, it is extremely difficult to achieve the teaching objectives of comprehensively improving quality of children.

\section{Reasons for the difference in practice curriculum for the Pre-school Education in Chinese and American universities}

\subsection{The difference in the education system}

It is generally known that, the teaching philosophy and methods of practical curriculum for Preschool Education in Europe and America show different characteristics compared with China. Chinese-style education focuses on expanding the quality and ability of students. The traditional model that combines theoretical knowledge with practical experience, to a great extent, cannot achieve the individualized development of students. Different from China, America recognizes the education mode that the service and learning transform into one another and integrate with each other. The American-style practical curriculum model for Pre-school Education realizes the perfect combination of the individual, school and family. The blended teaching is refined through the expansion of students' extracurricular activities and the combination of digital learning in nonteaching time and traditional teaching in classroom. Some application-oriented services software (supporting asynchronous instructional videos, comprehension questions, online answers, etc.) such as Moodle is applied in this process, which has greatly contributed to the healthy development of 
practical curriculum of Pre-school Education in American universities. Correspondingly, the education system in China focuses on teaching contents in the system while neglecting the social application. The practical curriculum of Pre-school Education can only provide very weak support for the students' social practice and work, which also results in the lack of effectiveness of the practical curriculum for Pre-school Education in China.

\subsection{The differences between Chinese and Western cultures}

Culture is the basis of people's behaviors and psychology. And the culture of a country is deeply imprinted on the daily behaviors and language communication of its nationals. The thought of Confucianism and Taoism in Chinese traditional culture has always affected the social and cultural development of China. The Tao Te Ching edited by Lao Tzu's disciples and students is regarded as the most practical and accurate version of Tao's thought. " 'Tao' is to preach and obey! However, "tao" is not limited to what we are talking about (one-sided), so don't be persistent but implement it in combination with practice ......" ${ }^{[4]}$ As the opening chapter of Tao Te Ching, this sentence clearly shows the connotation of its simple materialist philosophy. Its advocating of moderation and inaction also affects the development of modern social education in China and naturally penetrates into the practical curriculum of Pre-school Education. Specifically, students tend to have a utilitarian mentality for the study of the curriculum and lack professional scholarship. The pragmatic philosophy is advocated in America. The opposition to authoritarianism and authority has been its important content in the process of social operation, which also highlights its close connection with personnel training and social economic development. It regards the practical curriculum for Pre-school Education as the necessary way for the majors to serve the society and benefit mankind. Therefore, it expands the research on its practicability and constantly carries out the teaching reform in the field of pragmatism.

\subsection{The difference in kindergarten teachers and teacher accreditation systems}

China and American have great differences in the social status and benefits of kindergarten teachers. The development of early childhood education in China is very young and it is still a new undertaking. This makes the actual development of Pre-school Education, a major related to kindergarten teachers, is not very good, reflected in the uneven quality of students, poor employment orientation. Moreover, social development of kindergarten teachers is often considered to be the same as ordinary teachers. To a certain extent, this neglects the features of practical curriculum of Preschool Education. China stipulated the ways and means of acquiring teacher qualifications in the Teachers' Law in 1993, but its full implementation did not begin until 2001.In terms of teacher qualification, citizens of the People's Republic of China who are law-abiding and love education can obtain teacher certification through the education examination, and the supervision is relatively relaxed. The recognition of kindergarten teachers by American society is higher than that of China. The recognition and assessment of teacher qualifications in America lays more emphasis on the practical ability of Pre-school Education students; and only by passing three stages of examinations can they obtain the kindergarten teacher qualification ${ }^{[5]}$.

The social cognition and accreditation system of the Teacher Certification greatly affects the construction and development of the practical curriculum of Pre-school Education in China and America, and it is also one of the deep-seated reasons for the differences in the prospects for Preschool Education.

\section{Conclusion}

In conclusion, the construction of practical curriculum for Pre-school Education is aimed at training professional teachers for pre-school education. Due to the differences between China and America in education system, social culture, education qualification and other aspects, the practical curriculum of Pre-school Education in the two countries keep many differences in education philosophy, education implementation and many other processes. Only a better reference and study of relevant experience of pre-school education in America can help China better build a system of practical curriculum system for Pre-school Education. 


\section{References}

[1] Yang Qiu. Research on the Practical Teaching and Status Quo of the Operation Mechanism of Undergraduate Pre-School Education in Application-oriented Universities [D]. Chongqing Normal University, 2017.

[2] Dong Aixia. Comparison of Practical Curriculum of Pre-school Education in China and the United States [J]. Journal of Jilin Radio \& TV University, 2015 (09): 83-84.

[3] Cao He. Study of Undergraduate Education Mode of Pre-school Education in Colleges and Universities [D]. Shenyang Normal University, 2015.

[4] Wang Yuhua. A Comparative Study of Practical Curriculum in Pre-school Education in ChinaAustralia: A case Study of Qilu Normal University and Southbank Institute of TAFE [J].Journal of Qilu Normal University, 2013,28 (02): 19-22.

[5] Liu Ying. Comparative Study of Practical Curriculum of Pre-school Education in China and the United States and Its Enlightenment [D]. Shaanxi Normal University, 2011. 